\title{
FRUTIFICAÇÃO ALTERNADA EM CAQUI CULTIVAR POMELO (IAC 6-22) (1)
}

\author{
MÁRIO OJIMA $\left({ }^{2}\right)$, FERNANDO ANTONIO CAMPO DALL'ORTO $\left({ }^{2,4}\right)$, \\ WILSON BARBOSA $\left({ }^{2}, 5\right)$, ANTONIO FERNANDO CAETANO TOMBOLATO $\left({ }^{2}\right)$ \\ e ORLANDO RIGITANO ${ }^{3}$ )
}

\begin{abstract}
RESUMO
O cultivar Pomelo (IAC 6-22), mercê de sua bela aparência, elevada produtividade, facilidade de destanização e maturação precoce dos frutos, vem-se constituindo num dos principais hibridos de caquis taninosos lançados pelo Instituto Agronômico ao plantio comercial. No entanto, em lotes experimentais, tem-se constatado com frequiência irregularidade đe frutificação, isto é, a presença de plantas pouco produtivas, ao lado de outras com grandes produçōes. A fim de estudar as causas dessas frutificaçəes irregulares e, ao mesmo tempo, verificar a possibilidade de selecionar clones superiores desse cultivar, efetuou-se o controle da produção individual de 54 plantas, no período 1971-80, em um lote instalado em 1961, no Centro Experimental de Campinas (SP). Quarenta e oito das plantas controladas apresentaram produçðes marcantemente alternantes, embora a alternância das produçðes altas e baixas nem sempre ocorresse concomitantemente. Enquanto um grupo de plantas mostrava produçð̃es altas, outro, no mesmo ano, apresentava baixa frutificaçăo, verificando-se comportamento inverso no ano seguinte. Apenas seis plantas não acompanharam a mesma tendência, constatando-se, no entanto, que nelas a alternância de produção ocorria dentro de uma mesma planta, porém em ramos distintos. Não foi possível, portanto, selecionar qualquer planta capaz de proporcionar altas produçōes sem alternância, em conđições naturais. Observou-se, entretanto, em um experimento
\end{abstract}

$\left({ }^{1}\right)$ Recebido para publicação em 15 de maio de 1984.

$\left({ }^{2}\right)$ Seçāo de Fruticultura de Clima Temperado, Instituto Agronômico (1AC), Caixa Postal 28, 13100 - Campinas (SP).

$\left({ }^{3}\right)$ Divisão de Horticultura (IAC).

$\left(_{5}^{4}\right.$ ) Com bolsa de suplementação do CNPq.

(5) Com bolsa de aperfeiçoamento do CNPq. 
preliminar, que o desbaste precoce dos frutos, efetuado em plantas bem carregadas, além do aumento do peso dos caquis remanescentes, teve um efeito notável na quebra do hábito de frutificação alternante, proporcionando alta produção no ano agrícola subseqüente. Os resultados obtidos indicam que a alternância de produção, característica do caqui 'Pornelo', pode ser controlada, por meio da poda drástica de ramos no inverno e do desbaste precoce dos frutos em excesso, em anos de frutificação abundante.

Termos de indexação: caqui, frutificação alternada.

\section{INTRODUÇÃO}

Dentro de seu programa de melhoramento varietal do caquizeiro, a Seção de Fruticultura de Clima Temperado do Instituto Agronômico desenvolveu novas variedades de caquis pouco exigentes de frio, de vários tipos, podendo-se destacar os seguintes: Fuyuhana (RIGITANO et alii, 1983), Kaoru e Pomelo (CAMPINAS, 1980; SAO PAULO, 1983). O cultivar Pomelo (IAC 6-22) é uma seleção da geração F1 do cruzamento controlado 'Chocolate' x 'Hanagosho'. Os frutos são do tipo taninoso, grandes, globosos e de belo aspecto; as plantas são vigorosas e de alta produtividade. Essas características, mais a precocidade na maturação, facilidade de destanização e excelente. palatabilidade dos frutos, motivaram a divulgação do material para plantios comerciais, como alternativa vantajosa ao cultivar Taubaté, especialmente para a produção de caquis nas regiões de clima mais quente do Estado de São Paulo (CAMPINAS, 1980). O cultivar Pomelo apresenta como vantagem, ainda, a produção regular de flores masculinas em profusão, o que garante a autopolinização e, conseqüentemente, um bom pegamento de frutos, graças ao desenvolvimento normal de sementes (OJIMA et alii, 1976).

Entretanto, em lotes experimentais do Instituto Agronômico, em Campinas, Jundiaí e Monte Alegre do Sul, tem-se constatado, com freqüência, a presença de plantas bem carregadas, ao lado de outras pouco produtivas.

Procurou-se investigar como ocorriam essas frutificações irregulares, pelo controle da produção por planta, durante dez anos; aventou-se, também, a hipótese da existência de plantas matrizes mais produtivas desse cultivar, que deveriam ser selecionadas como clones superiores. A presente nota relata os resultados obtidos nesse trabalho.

\section{MATERIAL E MÉTODOS}

Utilizaram-se 54 caquizeiros do cultivar Pomelo (IAC 6-22), no espaçamento de $7 \times 5 \mathrm{~m}$, constantes do lote experimental instalado no Cen- 
tro Experimental de Campinas em 1961. Essas plantas, formando um lote homogêneo, estavam enxertadas sobre pés francos de caquizeiros comuns Diospyros kaki L.

Durante o estudo, a plantação recebeu os tratamentos mínimos indispensáveis, constituídos de podas de formação e de limpeza; pulverizações fitossanitárias de inverno e de verão; adubações e cultivo do solo, mediante gradagens e capinas manuais.

As produções de caquizeiros adultos - a partir dos dez anos de idade - foram controladas por um período de dez anos, de 1971 a 1980 . Anualmente, durante a segunda quinzena de fevereiro e primeira de março, quando os frutos se encontravam no estádio de maturação "de vez", procedia-se à colheita, em dois a quatro repasses, anotando-se, por planta, o número e o peso dos caquis colhidos.

Em cada ano, os frutos produzidos eram deixados a se desenvolverem livremente, até a ocasião da colheita. Constituiu exceção a esse procedimento a frutificação de $1976 / 77$, quando se efetuou um experimento de desbaste precoce dos frutos. Em novembro de 1976, nas plantas mais produtivas, fez-se o desbaste de cerca de $50 \%$ dos frutos em formação, quando se encontravam com diâmetro aproximado de $4 \mathrm{~cm}$.

\section{RESULTADOS E DISCUSSAO}

No quadro 1 , são apresentadas as produções médias, em número e peso de frutos, em dez anos sucessivos, de 54 caquizeiros cv. Pomelo (IAC 6-22), no decênio 1971/80. Para melhor visualização dos dados, as produçбes individuais foram reunidas em três agrupamentos $(\mathrm{A}, \mathrm{B} \mathrm{e} \mathrm{C})$, conforme o hábito de frutificação alternante, verificado especialmente no período de 1971 a 1976.

Verificou-se que, do total de 54 plantas examinadas, 48 apresentavam produções fortemente alternantes (grupos A e B). Essa alternância ocorreu essencialmente em função do hábito natural das plantas, muito pouco influenciado pelas condições climáticas do ano agrícola. Assim, os 26 caquizeiros reunidos no ḡrupo A apresentaram produções altas em 1971, 1973 e 1975, e quase nulas nos anos imediatamente subseqüentes, enquanto os 22 reunidos no grupo B mostraram também alternância marcante, porém produções altas nos anos pares, e baixas nos ímpares.

Ao contrário, apenas seis plantas reunidas no grupo $\mathrm{C}$ mostraram um hábito alternante não tão marcante como as demais. Nesse grupo, entretanto, observou-se que a alternância da produção frutífera se processava em áreas distintas da copa de uma mesma planta, ou seja, num ano a frutificação 


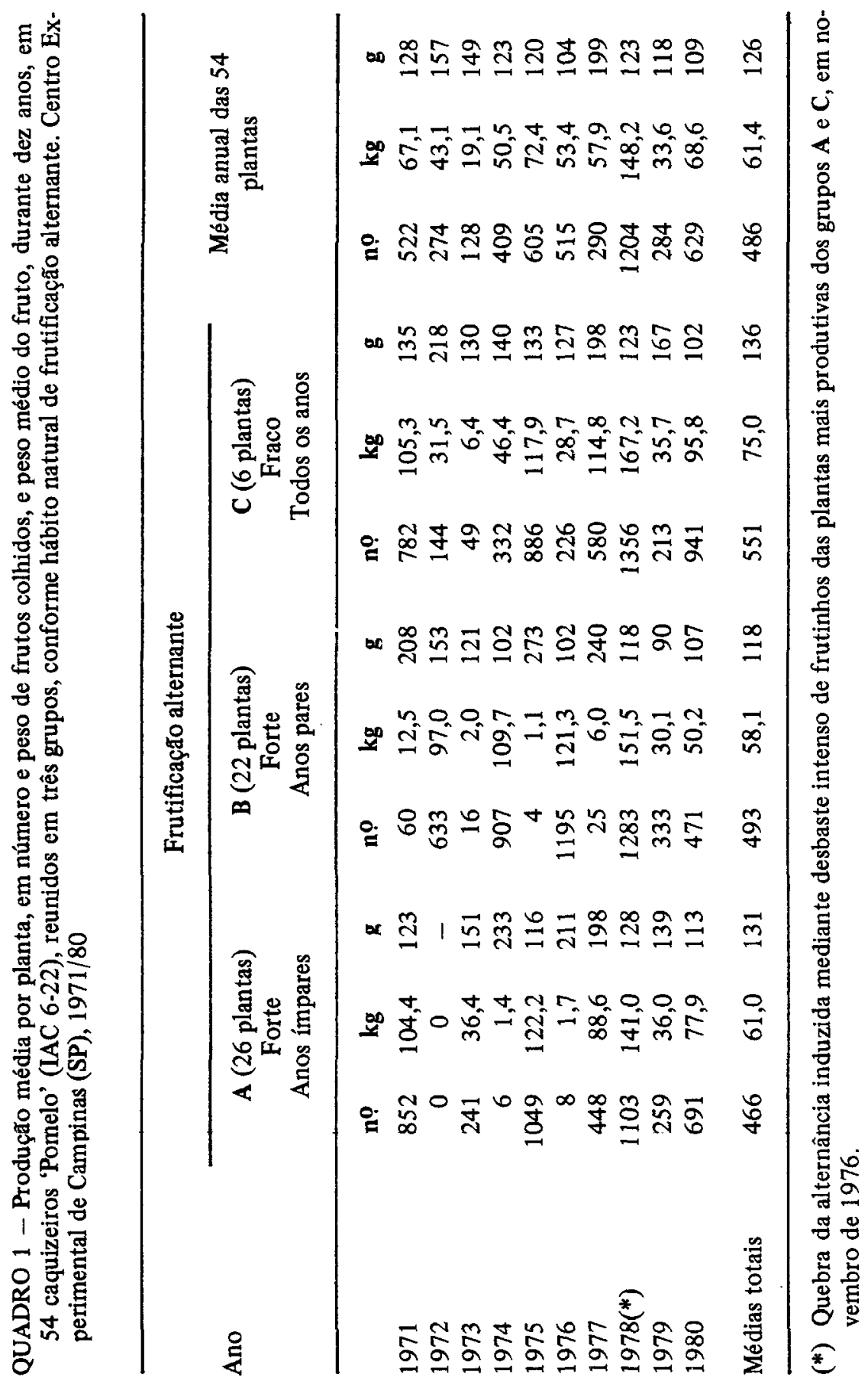


ocorria somente em metade da copa e, no ano seguinte, na outra, e assim sucessivamente.

Dessa maneira, não foi possível selecionar qualquer planta que, em condiçōes naturais, fosse capaz de proporcionar altas produções sem alternância, nẫo obstante as satisfatórias médias anuais do lote apresentadas no período do estudo.

No grupo $\mathrm{C}$ destacou-se, entretanto, uma planta excepcionalmente pouco alternante, que, nos dez anos de controle, proporcionou uma produção média anual de $124,6 \mathrm{~kg}$, bem acima das demais, e com média de $139 \mathrm{~g}$ por fruto. Foi esse grupo que apresentou, também, a mais alta produção média: $75 \mathrm{~kg}$ por planta, com frutos de $136 \mathrm{~g}$.

$O$ efeito do desbaste de $50 \%$ dos frutinhos, efetuado em novembro de 1976, nas plantas mais produtivas dos grupos A e C, fez-se sentir, de forma notável, na quebra do hábito de frutificação alternada, o que pode ser avaliado pelas elevadas produções verificadas na maioria das plantas desses dois grupos, nas duas safras de anos pares seguintes: 1978 e 1980 . Isso contribuiu para que aumentasse substancialmente a produção média de todo o lote experimental, que, em 1978 - coincidindo com a carga alta das plantas do grupo B, teve a sua safra máxima: 1.204 frutos pesando $148,2 \mathrm{~kg}$, por planta, enquanto a produção média geral do decênio foi 486 frutos, com $61,4 \mathrm{~kg}$. O desbaste influiu, também, no tamanho dos caquis produzidos em 1977, cujo peso médio foi de $199 \mathrm{~g}$, enquanto a média geral atcançou apenas $126 \mathrm{~g}$.

Após as pesadas cargas de 1978 , o lote voltou a apresentar, como era de esperar, produções alternantes, ou seja, baixa em 1979, aumentando novamente em 1980, naturalmente com algumas plantas em cada grupo fazendo exceção a essa tendência geral.

Os resultados obtidos nas condições do presente trabalho indicam que a alternância de produção, característica natural do caqui 'Pomelo' pgde ser controlada, mediante poda severa de ramos no inverno e desbaste precoce dos frutos em excesso, em anos em que se espera frutificação abundante. A adoção dessas práticas nas árvores mais produtivas deverá regularizar a frutificação em todo o pomar, de sorte a tornar possível obter altas produções de frutos de boa qualidade.

\section{SUMMARY}

\section{ALTERNATE BEARING IN PERSIMMON - CV. POMELO}

Pomelo, one of the main early persimmon selection developed in the breeding program of the Instituto Agronomico, Campinas, State of São Paulo, Brazil, tends to be alternate bearing, that is the trees tend to yield a high production in one 


\begin{abstract}
year followed by a low or no production in the next year. This tendency continues in the successive years unless some external factor may influence the natural set of flower buds. To obtain more information about the alternate bearing habit of Pome1o, annual yields were registered for each individual plant in 54 trees of this variety, at Campinas Experimental Center, during ten successive years (1971/80). It was distinguished three types of plant behaviour: group A -26 trees that bore moderate to heavy productions in the odd years and low or no production in the even years; group B - 22 trees that yielded alternatively also, but in an opposite year sequence; group C - six remaining trees showing a moderate alternate bearing habit, in which the successive yields were located alternatively on different branches of the tree. So, it was not possible to select any tree that did not show a type of alternate bearing habit, although the ten year average yield of the plot was high: $61.4 \mathrm{~kg}$ of fruit per tree, weighing $126 \mathrm{~g}$ per fruit. An early fruit thinning made in November 1976, pulling off about $50 \%$ of the young fruits of the trees from groups $A$ and $C$, resulted in a regular yield of large fruits in 1977, averaging $57.9 \mathrm{~kg}$ of persimmons per tree weighing $199 \mathrm{~g}$ per fruit, followed by the heaviest yield of the plot in 1978:148.2kg of fruit per tree weighing $123 \mathrm{~g}$ per fruit. The results indicsted there is a possibility of breaking the alternate bearing habit of Pomelo persimmon, and of improving its yield quality and size, through a strong thinning of young fruits on the most prolific trees when a large crop is being borne.
\end{abstract}

Index terms: persimmon, alternate bearing.

\title{
REFERENCIAS BIBLIOGRÁFICAS
}

CAMPINAS. Instituto Agronômico. Cultivares lançados pelo IAC no período 1968-1979. O Agronômico, Campinas, 32:39-168, 1980.

OJIMA, M.; CAMPO DALL'ORTO, F.A.; RIGITANO, O. \& IGUE, T. Estudo do pagamento e desenvolvimento dos frutos do caquizeiro e do seu relacionamento com a presença de sementes. Campinas, Instituto Agronômico, 1976. 14p. (Boletim técnico, 34)

RIGITANO, O.; OJIMA, M.; CAMPO DALL'ORTO, F.A.; TOMBOLATO, A.F.C.; BARBOSA, W.; SCARANARI, H.J. \& MARTINS, F.P. 'Fuyuhana' novo cultivar de caqui não taninoso para São Paulo. In. CONGRESSO BRASILEIRO DE FRUTICULTURA, 7., Florianópolis, 1983. Anais. Florianópolis, EMPASC, 1984. v.1. p.288-294.

SÃo PAULO. Secretaria de Agricultura e Abastecimento. Programa Paulista de Fruticultura de Clima Temperado - PRO-FRUTI. São Paulo, 1983. 96p. 